\title{
Making Change towards Inclusive Societies: The Soft Power of Community Archaeology in Building Cultural Heritage in Mozan, Syria
}

\author{
Yara Moualla and Gayle McPherson * (10) \\ School of Media, Culture and Society, University of the West of Scotland, Glasgow G72 0LH, UK \\ * Correspondence: gayle.mcpherson@uws.ac.uk
}

Received: 2 June 2019; Accepted: 21 August 2019; Published: 28 August 2019

\begin{abstract}
This paper investigates the soft power of community archaeology in transforming isolated and diverse communities into a more inclusive society, by reviewing community archaeology as a concept, and as a process, through the case of inclusive cultural heritage in Mozan, Syria. A theory of change underpinned key interventions in Mozan to track shifts in the social behaviour of locals from cultural isolation towards participation, partnership and inclusion, while investigating the process of establishing understanding, acceptance and mutual trust within communities. The research adopted an ethnographic study and used qualitative research methods. These relied primarily on direct observations and open ended, semi-structured and in-depth interviews with local communities, an archaeological mission and governmental and civic stakeholders involved in the area. The fieldwork research was informed by conducting a review of literature on the impact of culture and heritage in social contexts, social inclusion and cultural diplomacy. The paper demonstrates how the contribution of community archaeology in soft power change has assisted personal and community empowerment through inclusive cultural heritage on an individual level while strengthening social networks to mobilise the impact on the community as a whole. It reveals how such a project enhanced dialogue, increased awareness, and built and contributed to mutual understanding in order to support a shift in the harder area of symbolic community thinking and attitude, against a backdrop of conflict, war and isolation and builds the basis for inclusive cultural heritage tourism.
\end{abstract}

Keywords: community archaeology; inclusion; inclusive growth; soft power; cultural heritage; cultural tourism; cultural diplomacy; Syria

\section{Introduction: The Soft Power of Community Archaeology}

Since the contemporary term 'heritage' is a reflection of what has been constructed by past societies, based on their needs and ambitions, as well as upon a set of social and cultural values and norms, the concept of heritage can then be considered a symbolic product of a social construction that has the ability to make change in societies. This can be achieved by not only reflecting who they are, but also reflecting who they would like to become. Heritage, in that sense, can be seen as a dynamic since change and time play important roles in its representation within our current days.

Archaeology is considered one of the key components that feeds into the process of heritage making with continuous tangible material and intangible concepts, norms and values, therefore, archaeology used as a project has high significance for modern identities and cannot be seen in isolation of the context in which it is taking place. Archaeology has a power in society that can be seen in light of Nye's [1] concept of soft power as the ability to influence the behaviour of others to get a desired outcome without military pressure. In other ways it is in the intangible attributes [2] of archaeology, the cooperation and attractions that archaeologists can transform the archaeological resources into 
desirable outcomes such as inclusion within communities to help create sustainable cultural heritage. This paper will outline a specific case study that we examined over a number of years, both as a participant in the archaeological mission and as part of a wider study for the British Council. The unique access we were given allowed for an understanding of community engagement and development that would otherwise not have been possible. The paper introduces the key theories and concepts that underpinned our approach to the research, based on inclusion, diplomacy, power and inclusive cultural heritage and details of the case study approach. We then describe our research approach and methods and then present the results and discussion together to demonstrate the unified discussion of the key issues that emerged. Given the case study approach it was better to bring the results and discussion together into one section but with clear sub-sections to guide the reader. We finish with lessons learned for others and conclusions.

\subsection{The Rise of Community Archaeology}

In his article titled "What is community archaeology" Marshal considers that community archaeology is far from new, since people have always engaged with the pasts' related objects and places in the process of establishing meaning in the present [3]. Shackel suggested that one cause for the development of new community archaeology programmes is that an increasing number of archaeologists are accepting the fact that archaeology is more than the implementation of scientific methods to collect and interpret data and are more committed to the idea that communities have a sense of their own past and they want to be part of decision-making processes regarding their own heritage development [4].

Basically, the concept of community archaeology has gradually developed from being a preferable activity by certain archaeologists to becoming a soft power approach to wider policy implementation, political relationships and heritage protection while performing archaeological activities [5]. This transformation has been driven by different reasons concerning the preservation of the archaeological sites and the civic engagement and the development agendas in the area of excavation. Project directors whose political and community understanding were key to sustaining developments and empowering citizens were brought in to more multi-lateral projects to demonstrate the cultural value of archaeology in their communities. Grima [6] suggests three different ways to think about community archaeology. The ivory tower is the first way to look at it as archaeologists perceive themselves as the insiders and specialists with a privilege of knowledge that has served to widen the division between specialists' knowledge and experience and that of public knowledge. Another way of thinking about the relationship between the archaeologist, archaeological evidence and practice, and the public, is one which gives the archaeologist the role of mediator between the public on the one hand, and the archaeological resource on the other, or what is sometimes referred to as the gateway or the deficit model, as discussed by Merriman [7]. The third way is the 'multiple perspective model ', which recognizes the variety of perspectives, attitudes, and needs of different audiences, which will result in very different forms of engagement with the past [6]. This model also allows for the promotion of inclusive cultural heritage, a new concept for some in archaeological circles.

An understanding of archaeological resources, not only reduced site-looting, vandalism and encouraged preservation, but also created greater support for the curation of archaeological collection and records [8]. The work towards community archaeology drove archaeologists to work in a participatory approach, placing a high priority on educational and developmental activities with local communities in order to share the means of production of historical knowledge and promote the conservation of heritage [9]. Multivocality is considered a key component of archaeological practices and a core aspect of methods used in applying community archaeology. Hodder argues that multivocality is beyond allowing the participants more voices, more groups and more individuals as it involves changing practices and contexts so that disadvantaged groups have the opportunity to be heard and responded to [10]. Theories in cultural diplomacy also emphasise the aspect of allowing individual and communities' voice to be heard, to share with others and create mutual understanding 
and tolerance. Archaeology, through collective digs, allows groups to come together in a manner they may not otherwise have had the opportunity to do, to share a project, to manage, create and protect important parts of joint heritage. The British Council report on Cultural Heritage for Inclusive Growth suggests that when communities are inclusive and bring people together in creating and protecting their own cultural heritage it also allows them to promote their cultural heritage, in cultural tourism terms, thus contributing to their own social and economic development [11]. This allows, in some cases, collaboration, cooperation and the sharing of collective memory and rebuilding within communities for sustainable growth [12]. After all, in order to move beyond an understanding of the theoretical backdrop to archaeology work, archaeologists first need to situate their work socially, politically and economically [13]. The aspects identified are key components of cultural heritage and diplomacy and used in conflict prevention and resolution [14] and can be used to aid peace. As argued by Winter definitions of heritage tend to be framed as an inheritance, a source of identity, as an assemblage of values, discourses and materialities, or more broadly as a mediator between the past and present, human and non-human [15]. That said, there is also counter-evidence as Le Baron observes that: 'Culture is an essential part of conflict and conflict resolution. Cultures are like underground rivers that run through our lives and relationships, giving us messages that shape our perceptions, attributions, judgements and ideas of self and the other' [16]. Thus, the very thing we are trying to use to demonstrate can be used as a tool of, and in, soft power change, is contested and challenged. The reason that culture is so precious is it assists in the role of aiding mutual understanding, tolerance and increasing resilience amongst community groups but also presents the opportunity for inclusion, personal and economic growth and sustainability in cultural tourism terms [17].

The production of knowledge is historically positioned, and McDavid [18] argues that it is important to take into consideration the social and political constrains in any particular community, when deciding whether or not a public or cultural intervention and interpretation is possible within that community. McDavid also argues that critical theory calls for self-reflection by the social analyst and any social actor should be seen as a part of the social process analysis [19] thus understanding that the representation of culture is one that is created for a given process or product.

She considers the act of interpreting publically that material culture is political because it reflects the way in which people continue to negotiate social and political power and because it incorporates ways that people are affected by the public presentations of what she calls sensitive archaeological and historic materials [18]. McDavid used Cornel West's term "critical organic catalyst" to refer to community archaeology as a work of public intellectuals where the mandate is to relate disciplinary skills and agendas to a "collective praxis" by engaging activity in large social and political present [19]. Brooks stresses the importance of public involvement as without public involvement there cannot be effective public support of archaeology and without public support there cannot be legislative funding of adequate programs to recover and protect a state's or the nation's archaeological heritage for those communities and tourists alike [8]. In order to understand the concept of community archaeology, it is vital to discuss the term community and its related dimensions in this regard. Since communities are seldom mono-cultural and are never of one mind, as they are combinations of people who have come together for many different planned and contingent reasons, Marshall argues that the interest of community may change over the course of time and during any archaeological project in their area [3]. Smith and Waterton also revisited the notion of 'community' within the field of heritage, and discussed the multi-dimensions and layers of communities that might lead to tensions between different groups and as their aspirations arise and are mediated, especially when defining and negotiating what brings them together in terms of memory, place, identity and cultural expression [20]. It is necessary for archaeologists to understand how local people view themselves and their histories in order for archaeologists to define how young people should be taught history and how they deal with sensitive issues in their past [20]. Trigger [21] remains committed to the notion that it is the archaeologist's responsibility to seek an objective understanding of archaeological data by revealing biases in archaeological interpretation and by the systematic testing of interpretations against a broader 
data base, notwithstanding our differences in nomenclature [21]. As for multivocality, Trigger believes that the more questions that are asked and the more narratives of the past that are formulated the better. He equivocally opposes the idea that any specific group should be accorded an exclusive right to control the interpretation of their own past. He also rejects the suggestion that all narratives are of equal historical value. Multivocality in Triggers view enhances rather than relieves the need for archaeologists to weed out erroneous assumptions and interpretations and to synthesise divergent viewpoints to produce more holistic explanations of the past; in turn allowing the possibility of inclusive heritage development. The claims of the past are sometimes contentious as different groups agenda will often clash over claiming a role in the official public memory, causing the established collective memories to be continuously in flux [4].

To put the community context within the archaeology social practices, it is important to look at community archaeology's most distinguished characteristic as viewed by Marshall as it is the act of shifting at least partial control of an archaeology project to the local community or communities there [3]. Clarke's [22] view on community archaeology is consistent with the other mentioned scholars as she argues that community archaeology aims are to encompass approaches that include community members in decision-making about research topics, research sites, analysis of data, curation and management of collections and the production of materials that are culturally appropriate and useful for heritage management and tourism development [22]. Clarke considers several components as integral to a community-based approach, and the way they manifest on the ground may differ from community to community and from project to project. She argues that the character of a community project will circle around a diverse unpredictable and even indefinable range of factors. These factors can be personal aspects such as the motivations and commitments of individuals and social grouping within the community, therefore, the form and the direction of a community-based archaeology may be structured by the stimulus and rationale for the work. The nature of the project whether it is a community or a researcher driven project, the local history and experiences of interactions with non-local society, the structure of community and its representative organisation all play an important role in determining how a project will be shaped [22]. It is important to highlight Clarke's view that even though the character of community archaeology will vary according to project, place and people, there are some common elements that can be identified. These elements include the use of effective and culturally appropriate media to communicate the project, the idea that negotiation of project boundaries is an ongoing process and the recognition that archaeology is generally carried out in other people's social place.

Community archaeology can be an effective tool if community archaeology projects are conducted with conscious attention to the context of the diverse communities hosting it, putting into consideration the different factors that might affect its process, mechanisms, results and impact on communities to ensure it is really inclusive cultural heritage [16]. How an individual or local community creates meaning of the past can reshape perceptions of national collective meaning ties in with government cultural policies and international protection and promotion of heritage. This reiterates Smith's [23] view on cultural heritage as a performative process of meaning making, linked to the negotiation of various forms of cultural and political identity [23,24]. Cultural heritage in Smith's view is seen to derive social change, with the ability to help negotiate the social and political narratives as she wrote: "values that reflect the needs of the present; in this process social and political value, and the narratives they justify, are created and recreated, and heritage is linked to processes of remembering and commemoration, and emotion is crucial to that process" [23]. Various individuals and groups can transcend barriers to be part of a collective memory, with a common past, present and future [4] and that is what interests others to visit and help contribute to the inclusive growth of cultural heritage.

As archaeology is considered a process to produce heritage and heritage is considered necessary to sustain local identities and a sense of a place, especially by those communities and locals that are threatened by transformations in the global economy, [4] in addition to other threating factors like armed conflicts, the use of archaeology in soft power change is increasing in Syria. There is evidence 
in other post-conflict regions, such as Columbia, of cultural interventions being used to re-build communities leading to peace, tolerance and mutual understanding [25] and cultural tourism and sustainability of small heritage businesses [25]. As for the impact of globalisation, there is a strong sense among some archaeologists and cultural diplomats that by including communities in the decision making process, through the meaning of either participatory or collaborative approach, they are helping to create a sense of heritage for that particular group, therefore, archaeologists can embrace the various and diverse histories found in any one place or community aiding the peace building process $[4,25]$. Therefore, heritage can be seen as a performance to underpin identity, particularly national identity. The affective/emotional responses of individuals are central to this process, and animate responses to and uses of the cultural items, places or events that they deem to be 'heritage' as a range of affective practices are embodied in the processes of heritage making [24,26].

In the end, archaeological excavations have the power to transform a specific locally isolated geographical spot into a cultural heritage location with a lot of attention from different organisations. This process can transform the society's behaviour positively or negatively based on the social cultural policies applied, therefore, community archaeology can lead this process and help the positive transformation of the place [27].

\subsection{The Case of Mozan, Syria}

The case of Mozan can be explained here in terms of how community archaeology triangulates archaeological processes and cultural policies in a place with the archaeological findings from the site and the local communities living in the area of the archaeological excavations. The success of this triangulation in Mozan supported the social fabric incubating the archaeological site, which led to the protection of the archaeological site during the difficult circumstances of unrest and conflict in Syria and can hopefully post-conflict, lead to a cultural heritage attraction.

This case aims to investigate the change in social behaviour amongst locals and between locals and the foreign archaeological mission and other national partners and stakeholders involved in the region to reach an inclusive society. It is important to understand that there was no single activity or a clear recipe that led the change towards inclusive society in Mozan, rather it was about the interactive bottom up approach adopted by the archaeological mission there and the network of partners and stakeholders as well as the methods, tools and mechanisms applied in the region.

What has begun as a traditional scientific excavation mission more than 30 years ago has been transformed into an inclusive cultural heritage approach. This change happened through three phases:

- The first phase started with the beginning of the archaeological work in the area, that soon adopted an inclusive cultural heritage approach that combined everyone in the area whether during the fields daily work or through the analysis of the site findings. Further discussion took place regarding how the activities changed the community in Mozan is further discussed throughout this paper, however, it is worth mentioning and this happened through systematic scientific training; to shape a field expert from the local community rather than a random worker that can be replaced easily and through a great deal of awareness campaigns and school visits to the site. Furthermore, providing the right conditions to include everyone in the area in the scientific work on field and during analysis and studies of the findings is important.

- The second phase happened during 2011 and 2012. This phase was led by the management unit of cultural heritage transformation project, the cultural department of Syria Trust for Development back then. During this phase many stakeholders and partners came together to deliver a cultural base community development program in the area.

The aim of this program has been articulated by one of the program executives as "Our goal was to put strategic outlines for cultural based community development that empower people to reshape their own cultural and inherited identity, people to become more actively responsible towards 
their cultural heritage, enhance their abilities to be able to protect their reach heritage and insure its sustainability as an important economic resource".

The main networking and funding activities were:

- Building a flexible network from the governmental, civil and private sectors such as Toumohi institution, Syrian Youth Council "Nakoun", Moubadroun group supported by the British Council and the Syrian Enterprise and Business Centre "CEBC", as well as the Directorate General of Antiquities and Museums and the archaeological mission.

- Providing two scholarships dedicated for two young women to study at the university.

- Establishing the Gate of Urkesh that included Urkesh women workshop for handicrafts, Kids club and kindergarten and the centre for capacity building.

All the work conducted in this phase was part of a pilot project to test and revise the community development strategy within the cultural vision and policy of the Syria Trust for development. For the archaeological mission this phase was important to build knowledge and experience as well as networks to reach the Eco-Archaeological Park to insure sustainability for both site conservation as well as tourism as a complete experience. The third phase represents the follow up by members of the archaeological mission during the conflict from 2013 until now. During this phase financial and technical support has been provided to locals in order to keep preserving the site whether from a long distance by the head of the archaeological mission or through the local team to make sure that the projects of the second phase are still running to support the locals there, create new initiatives like touring exhibitions in the region, as well as keep the awareness campaigns running to conserve the site and the vision for the Eco-Archaeological Park in the future. The international team abroad is organizing international exhibitions of the site and the inclusive work that led to preserve it during conflict. The fieldwork in Mozan contains many relevant factors that can lead to conflict or inclusion based on applied policies and interventions, as the region contains 21 Kurd villages and one Arab village in Northeast Syria very close to the Turkish boarders. Social conflicts could have occurred not only due to the different ethnicities inhabiting the area of study, but also to other dimensions like different social classes, gender issues, as well as dealing with a foreign archaeological mission over a long period of time.

\section{Materials and Methods}

\subsection{Research Approach}

This case study approach tracks the shift in the social behaviour of the locals from isolation and indifference towards participation, partnership and inclusion and investigates the development of building understanding, acceptance and mutual trust within the communities there as objectives towards the long-term aim of integration through different interventions. This, in turn, led to sustainability of key communities and offers the potential for inclusive growth in cultural heritage and cultural tourism, post conflict. The aim was to achieve soft power outcomes and positive values in the region, by mobilising cultural diplomacy policies to facilitate people-to-people communication and mutual understanding. We examined the bottom up approach adopted in these initiatives and local participation in shaping the approach from the planning phase, with a careful attention to the unique context of this case study. The region reflects the Syrian cultural diversity, yet it is very remote from the Syrian capital, Damascus. In addition to the constructive relationship between the local communities and the archaeological mission Director, the national authorities oversaw a long distance management plan that helped the local people maintain the site.

The study sought to examine the impact of the tangible and intangible outputs as a result of the various interventions in the area of Mozan, and produce soft power outcomes that feed into the long-lasting goals of community archaeology, cultural heritage development and cultural tourism [28]. A theory of change utilising cultural diplomacy and specific interventions was used to guide this process and follow a logical model for analysis of the results. 


\subsection{Research Methods}

The methods used to investigate the proposition were qualitative research methods using open-ended, semi structured and in-depth interviews. In addition, participant observation was used when working with the NGO and the group of individuals working on the actual evacuation dig. This approach to gathering data was possible due to the unique relationship that had been built up with the NGO and allowed for a less structured approach giving the interviewee more freedom to direct the flow of conversation especially as they were familiar with the interviewer [29]. The interviews included five male and three female locals from the Kurd and Arab communities living there, 15 personnel from the national stakeholders involved in the area such as the municipality, the mayor of the region, Directorate General of Antiquities and Museums (DGAM), as well as the archaeological mission still working on a long-distance basis and the parties involved with the cultural-based community development project (a set of experts, Syria Trust for Development, Tomohi, Nakoun, DGAM, and other related bodies). McGill highlighted the importance of including a range of institutions and individuals in heritage work (e.g., community residents, universities, students, regional heritage professionals, NGOs, cultural organizations, governmental institutions) and demonstrated that close observation of heritage projects helps to develop understandings not only of the communities interacting with heritage places, but also helps archaeologists to understand the impacts and implications of the projects in which they engage for future cultural tourism use [30].

McPherson et al. suggests that the framework for comprehending a project and tracking evidence of change might be required at an individual project level, and when using a logic model a project can be mapped out completely [5]. It may have outcomes which are soft power-related, for example, an outcome can be improving relationships and by following a logic model, we can ask, which of the aims, objectives and outcomes relate to, or constitute, soft power outcomes related to inclusion. Given what we understand from the detail of the logic model, McPherson asks what broader lessons about these types of interactions, engagements and activities can be translated into the theory of change. Using this model in the case of Mozan we argue that it might prove a valuable process of reflection. The secondary method in gaining knowledge and insights to support this case study was through reviewing relevant literature and related policy documents.

Data from the interviews, and from the policy documents and reports reviewed were examined around meta-themes of soft power, understanding, resilience, confidence, mutual trust, empowerment, cultural heritage, sustainability, tourism, engagement and cultural diplomacy for analysis. These were then used along with key statements from the interviewees and from the participant observations undertaken to inform the success, or otherwise, of the community archaeology project in the case of Mozan, and whether this contributed to a soft power change and a more inclusive environment for growth in cultural heritage for the communities living in a conflict zone.

\section{Results and Discussion}

\subsection{Comprehending Community Archaeology in Mozan: From Mutual Benefit to Mutual Respect: International Knowledge Meets Local Experts}

Buccellati, as the head of the archaeological mission excavating in the area of Mozan, worked for more than 30 years to understand how local people in the area view themselves, their histories and how they dealt with sensitive issues in their past. As he explained while being interviewed:

"What derived (sic) me to work very close to local community and engage them with the analysis and the results of our archaeological site was not only connected to my basic belief in human common values, but also my strong belief that we share a symmetrical relationship with the local communities. Local people have an instinctive relationship to the territory and the land, which we archaeologist don't have. But most of the locals don't have interest in the past while we have a great interest. In another words, we know more about the ancient Urkesh, but they know more about Mozan. (The) local community can tell us a lot about the 
territory and by working with them we can learn a lot about how ancient Mozaniens used to manage the land."

The diversity of the community/communities and the conflict of interests that might arise at any moment is well comprehended when looking at Buccellati's archaeological work in Mozan/Urkesh. The social context of the Mozan archaeological site reflects Marshall's views on communities, its nature and diversity [3] at the core of Buccellati's consistent work, not only to comprehend, reach for, and work with these communities but also to be part of these communities, called by a local name "Abu Iskender" as a symbol of familiarity and friendship and being an anchor of trust by the communities there. As Buccellati revealed "The ultimate factor of success in building a relationship with community is to start with a position of trust. We showed our respect to their traditions and were sensible to their society specifics and as a result we become a family as we always felt that they are our extended family".

Buccellati has also looked at the local communities beyond those who lived on or close to the site as he managed to comprehend the nature of the overall area and build relations and network with interested groups and bodies that share the same concerns and interests on a regional and national level. Buccellati was completely aware of the overlapping nature and the conflict that may arise between the different communities there in addition to the interested bodies on a regional and national levels, especially because the Urkesh or Mozan archaeological sites represent an Indo European civilisation amongst a Semitic area. He managed to turn the site into a place of convergence of interest, facilitating dialogue while discussing the history, meaning and significance of the place instead of being a site of conflict and clash of identities. Being able to be part of the mission and acting as a participant observer in the research process allowed us unique access to work with the different community groups.

\subsection{Empowering Communities: A Heritage Site for Everyone}

The community archaeology approach adopted in Mozan/Urkesh enabled Buccellati and his team, as well as the network that worked in the region later, to build the cultural heritage-based community development project, to ask questions about the past, to see archaeological remains in a new light and to think in a new way about how the past informs the future. It gave hope for the archaeological site to remain conserved and protected by its local communities as he successfully transferred the ownership of their own past. This presents an example of the role of archaeology as soft power cultural diplomacy; influencing those in power by engaging with those at the grassroots and empowering them to fight for their culture and heritage and have their voice heard, a voice that can tell the story post-conflict to cultural tourists and help the area grow economically and socially again.

Buccellati's direct engagement with the local communities and his strong belief and desire to transfer ownership of the place to them was reflected by the field practices, data collection and analysis as he depended mainly on locals in the field, and provided them with the necessary training and knowledge to become local experts rather than a regular workers that can be replaced by any one. These soft power outcomes of training, education, ownership, confidence and mutual trust are all key deliverables in the theory of change Bucellati considered important and one of the authors was able to observe. Bucellati was a key informant for this research and revealed that he also dedicated many events and evenings to explain the site's new findings to the locals, guided many school visits and provided the site's different parts with educational information and signs, making the archaeological site accessible for all locals and demonstrating the role of a cultural archaeological project in the sustainable development of heritage and as a key vehicle for cultural diplomacy. Sharing and celebrating new archaeological finds and data helped Buccellati to become part of their group and not simply circulating data with them. In other words, they were subjects participating in his project rather than objects of his project. One author was also able to be part of this group at different times and, as a native speaker, this helped enormously with language barriers, networks and inclusion. 


\subsubsection{Common Ground for Further Development}

Buccellati's commitment from the very beginning to comprehend and engage with the local communities, as well as his strong partnership with the Directorate General of Antiquates and Museums, in addition to the positive relations with local and regional authorities, made him fully aware of the local needs in the area while foreseeing the development's potential that his project could make to the area locally, regionally and nationally. This close relationship and positive dynamic with the locals enabled Buccellati to understand the local needs and interests leading him to extend the archaeological vision to create an eco-archaeological park in the region aiming to safeguard the integrity of the place and participate in the sociocultural development of the region based on the local special characteristics, needs and skills. This managed to get a positive response from the regional and national authorities, due to Buccellati's strong partnerships that he created over decades based on dialogue, mutual understanding and trust. Therefore, Buccellati's proposal was in harmony with the national cultural vision and policies to develop the area but from a bottom up approach, based on the actual local needs and potentials.

\subsubsection{Public, Private and Civil Partnership to Inspire Community Participation}

The Gate of Urkesh managed to create a hub for interested bodies from the governmental, civic society organisations and the private sector to intervene and work in the area in a sustainable, if not a resilient, way leaving locals with soft power skills, better understanding of active citizenship and a strong voluntary foundation that enabled them to protect their site at the time of difficulties and conflicts. Evidence of the partnership and network approach here resulted in a more a connected community as explained by the operations manager of one of the involved NGOs:

"We came to the area with the aim to connect with diverse communities there, engage with the youth. We were looking to facilitate the establishment of a platform where people can discuss their problems, reflect critically, realize their social and cultural resources and to come with their own initiatives. Then we intervene again to empower them by suggesting a vast and diverse network of professionals, experts and funders to insure a positive realization of local projects in the area."

Buccellati's archaeological work in Mozan/Urkesh is also in line with Shackel's view of community participation, which means that archaeologists are no longer the cultural broker they once were. Practitioners are beginning to recognise that many histories can exist in any one place, and these stories of the past are continually being shaped and reconstructed. Archaeologists should address these changing perspectives and they need to respond effectively to the challenges and opportunities to ensure the authentic narrative is sustainable for generations to come [3].

\subsection{The Dynamics towards Inclusion}

In order to understand the dynamics towards social inclusion and its connection to community archaeology, it is vital to spot the nature, causes and consequences of social exclusion, while tracking the relevance of community archaeology in building an inclusive society, by investigating the potential of cultural heritage projects in building the social and cultural participation of diverse societies beyond the economic dimension and discuss its power in enhancing opportunities, access to resources, while empowering everyone's voice and respect for rights. An understanding of the concept of social inclusion and how this concept has been derived from the concept of social exclusion is important at this point as it offers an original perspectives on the social world because it has the potential to provide new insights into the nature, causes and consequences of poverty, deprivation and discrimination [31]. A simple definition of social exclusion is suggested as: the process whereby certain individuals, groups or communities are pushed to the edge of society and cannot participate fully because of poverty, inadequate education or underdeveloped life skills and was useful to our work here [17]. 
A number of scholars as well as institutions, Mathieson et al. [31] described the different ways that define social exclusion to reflect its different institutional, political, historical and geographical context. The concept of 'social exclusion' is then contested, and has multiple and multi-layered meanings. These meanings are being continually redefined over time and have different policy implications. Thus, the term 'social exclusion' has been used to describe: groups at risk of exclusion; what people are excluded from; the states associated with exclusion; the processes involved and levels at which they operate; and the actors involved. There is some consensus that 'social exclusion' is: (a) multidimensional, encompassing social, political, cultural and economic dimensions, and operating at different social levels; (b) dynamic, impacting in different ways to differing degrees at different social levels over time; and (c) relational [31]. As a result people may be excluded from some, but not necessarily all, aspects of daily living. People can be excluded from production by not being able to access employment or education, or from consumption when they cannot afford goods or services. People can also be excluded from social networks when they lack access to social, sporting or cultural organisations and even excluded from decision making when they lack power to change personal or wider circumstances [17].

\section{Social Exclusion in Mozan}

The context of Mozan tracks a lot of what can be considered the results of social exclusion, as people in the area with the exception, of the seasonal work they have at the archaeological site, have no other means of employment. This was reflected while interviewing a project director of one of the involved NGOs in the area. He said:

"Recalling our initial work with young men in the area, the biggest challenge was to discuss with them the possibility of a locally based future for them. They all agreed that the area doesn't have any future horizon, especially for those who had university degree. Therefore, we set the goal of creating an attractive atmosphere for youth to stay and realize their future plans."

Access to public and private services are limited, although schools are available, the closest medical centre is $15 \mathrm{~km}$ away and basic grocery and bakery services are also located in Amouda. Transportation is limited, although villages in the area are very close to each other but people there present a closed image. They are not willing to build real social networks and visits amongst families are limited to official occasions, such as funerals and weddings. There are no neighbourhood centres or parks for families to meet casually, people in the area do not know how the system works and, as a result, there is a low level of trust when it comes to local authorities in the area. Exclusion then can be on different social, cultural, economic and political dimensions. The aspects of social dimension are reflected by isolation, few social connections, poor coping skills, lower level of confidence and fear of crime. The cultural dimension meaning for people is the difficulty of understanding themselves and reflected by being seen as different, outside the loop, grinning and bearing it and keeping their heads down. The economic dimension is understood and felt by many as people being unable to afford a decent standard of living and this is reflected in many experiencing poverty and deprivation, poor housing and receiving low wages/benefits. The political dimension is understood here as people not having representation and this is reflected in not knowing how the system works and, as such, they are not involved in networks, are disengaged, dissenting and not voting [31]. These different dimensions have been investigated in Mozan and helped shaped the indirect questions of the open-ended in-depth interviews. The aim was to investigate, on the one hand, the level of participation and partnership in the area of Mozan as preconditions of an inclusive diverse society and, on the other hand, discuss the social inclusion indicators of understanding, acceptance and respect on different dimensions and scales. As one member of the archaeological mission stated: "it is not enough to expect a bottom up approach from the locals and expect inclusion, this needs to be supported by government policy to enable inclusion". 
Only by understanding what leads to social exclusion, its multidimensional nature and its various scales, it is then possible to comprehend what can be considered an inclusive society or propose practices and processes to achieve such a state in society. Social inclusion can then be defined as a series of positive actions to achieve equality of access to goods and services, to assist individual participation in their community and society, to encourage the contribution of all persons to social and cultural life and to be aware of, and to challenge all forms of discrimination [17]. Accordingly, social inclusion processes involve more than improving access to economic resources and this is clear, too, when defining social inclusion as a process to improve the terms of participation in society, particularly for people who are disadvantaged, through enhancing opportunities, access to resources, voice and respect for rights [32].

\subsection{The Relevance of Community Archaeology to Inclusion Practices}

It is the multi-dimensional nature of social exclusion that has contributed to the interest it has received within a diverse range of professional spheres. Now, within a framework of social exclusion, responsibility is more widely shared-a broader range of institutions are considered as having a role to play as part of a multiagency approach to tackling the symptoms and causes of exclusion [33]. This is why community archaeology is considered an important medium in soft power change especially since archaeological excavations often happen in remote and less developed areas where people are more fragile and exposed to social exclusion and isolation.

Within the social dimension, one might consider the importance of self-worth, dignity and the importance of community identity, which, if damaged, can lead to social disintegration. The opportunity for social participation and its effects on the social fabric of the community is important, as it involves relational ties between individuals and society and individuals and the state. This was well reflected by what a local woman said in the interview:

“I can't describe my feelings when they organized an exhibition in Aleppo for our handicraft creations, I couldn't believe that many people came to see our work and actually many travelled from our area to Aleppo to support us. This was something I will never forget."

The notion of cultural tourism was new to the people we engaged with and the concept of cultural heritage as business and industry is only just beginning.

Other issues to be considered within the social dimension include the opportunity to participate in decision-making and the marginalisation of disadvantaged groups [33]. Díaz-Andreu challenges archaeology to help form collective identities for communities who are not direct descendants of those who created them, questioning the role of archaeology in public participation and challenging the fact that sharing archaeological knowledge with the public needs to go further than information giving, but information sharing, for an archaeologist and heritage expert to really engage in community participation [34]. This symbolic power of archaeology as a means of communication and social inclusion is particularly important for the case of Mozan, since the archaeological site belongs to the 3rd millennia B.C. and the area is a mix of Kurds and Arabs with no direct link but the excavation to the site. The second phase of the inclusive work in Mozan has a focus on the concept of community participation by shaping the volunteering infrastructure for youth in the area and making it one of the selection criteria for the scholarship program. Indeed this concept was at the heart of the second phase in 2011 and 2012 that started with the active citizenship workshop to engage with the local communities.

\subsubsection{Strengthening the Sense of Belonging and Empowering Local Groups}

Engaging with community archaeology and heritage projects not only reinforces the need for communities to come together, it enhances the relationships. Partnerships and networks are developed during the different stages of the project in order to enable and encourage people to become active agents in their communities, resisting terrorists groups, developing resilience and building shared understanding. This was well explained by another local woman in the area: 
"Participating in this project made us realize how simple it is to get to know each other, to become friends, to trust each other and to work together. Actually, it was not as complicated as we always thought. Simply we were eager to know each other better, enthusiastic to succeed and brave to try."

Since community archaeology, whether with its participatory or cooperative approaches, can play an important role in building the inclusive cultural heritage, it has the potential to bring people together, as explained by a beneficiary woman from the Gate of Urkesh project:

"This project was a breakthrough for the women in the area (Kurds and Arab) as it provided a comfort place for more than 30 women to get closer, chat and work ... discover the uniqueness of each woman in the area, and it also provided us with economic independence, self-realization and respect. Men used to meet at the archaeological site, work together and talk."

When communities are engaged with cultural activity, or, in this case, a heritage formation process through an archaeological project, this can help to increase communication and social skills. For example, widening social networks, while supporting individual confidence in addition to integrating immigrant groups with its hosting societies. In turn, the new products and tourists flowing to the area to see and consume their work achieves one of the objectives of the projects and demonstrates soft power change in action.

Art and cultural engagement can play a positive role in raising people's aspirations and making them aware of the opportunities that are available to them both within and outside their communities and this aligns well with developing soft power skills through the use of art and culture [31]. The case of Mozan helped to open the horizon of the youth in the area through different workshops to help communities to comprehend the opportunities available to them, while empowering the students to proceed to university through scholarship programmes for the girls in the area of Mozan, as well as training and discovery visits to Damascus to create networks and gain knowledge [25]. Skills development and training opportunities are key areas that those in government, NGOs and cultural institutes, such as the British Council, want to see up-scaled to help others in key conflict zones. The UK is currently working with 12 countries (interview with BC staff) in conflict or post-conflict situations and understanding how to use culture as a contribution to the development of soft power skills to help resilience, confidence, empowerment and social inclusion is a key outcome.

\subsubsection{Supporting Communities to Reach Out from Within}

The result of these links above is reflected in the "Gate of Urkesh" a cultural-based community development project. The project, led by civil society organisations, managed to engage local communities there, together with the archaeological mission, and other related civil and governmental parties. It is clear that cultural participation can lead to the development and enhancement of many skills and competences. Such engagement in cultural activities has been found to result in: the gaining of new skills improved informal and formal learning, increased self-confidence, self-esteem and feeling of self-worth, the improvement or creation of social networks, an enhanced quality of life, the promotion of social cohesion, personal and community empowerment, and improvement of personal and local image, identity and wellbeing. McPherson et al. [25] revealed that longitudinal projects were more likely to demonstrate a soft power change in, and from, Governments, internationally to how they view and deal with that country. The results revealed that, locally, the project empowered young people to have more confidence, build resilience, and have mutual understanding of others. Practically, we also found that art and culture policies that lead to community engagement, storytelling and exchange of cultural heritage can have lasting effects that can aid in conflict prevention and help grow the development of cultural heritage, especially as opportunities for women.

People in Mozan had the chance to know each other better through the process adopted by the archaeological project and other related initiatives and parties. They listened to each other, discussed their stories, visions, problems and hopes. This helped them stand on a common ground. We also 
found that those that utilised the long lasting traditions of arts and cultural production were able to help validate people's stories (the intangible cultural heritage) and perspectives by bringing people together to discover shared goals and strength. This process can broaden citizen voices and participation, offering a welcoming entry point to those who have not felt power in the civic realm before. This can enhance the quality and capacity for dialogue. The arts, in the wider sense, can promote greater awareness and understanding of issues, contributing to shifts in thinking and attitude [35,36].

\subsubsection{Inspiring Social Action}

Another factor that can be at the core of shaping identity and a sense of belonging is the nature of the archaeological work as a process to produce heritage; therefore, people engaged in these practices are a focus of local cultures and traditions and often become more engaged in their communities which helps the inclusion practices through social connectedness, participation and partnership, which, in turn, empower the indicators of social inclusion like understanding, acceptance and mutual trust. Díaz-Andreu also believes that archaeological heritage can become a vehicle with which to talk about aspects of social cohesion, in solving social tension and positively reinforcing identity [34]. A Syrian member of the archaeological mission has articulated this:

"Our work as archaeologists should not be limited in excavating past artefacts with static and nostalgic values, but should include a serious search for values that support our present and impact our collective conscious as modern Syrians. Urkesh in this perspective played an important role in the forth and third millennia B.C. and continues to be important in our current era."

The case of Mozan discusses how community archaeology, as an example of culture as soft power change, helped to achieve that and, to an extent, it helped reduce barriers and prevented conflict, especially in a diverse area like Mozan, whilst growing opportunities for inclusive growth in cultural heritage. The case study in Mozan has shown, as an example, that people can, and are, making significant civic contributions as catalysts, conveners, forums and forms of civic engagement and social action. They are enhancing awareness, knowledge, and discourse around the key issues identified above, and were able to confirm a shift in attitudes, an increased capacity, in skills, resources and status to engage in civic concerns, promote effective participation and action as well as improve systems and policies that ensure social justice and create a sustainable environment. Others have discussed this in terms of developing cultural capital in local actors and helping local people to act as agents for change $[35,36]$.

\subsection{Lessons Learned}

Location is very important in terms of understanding the context and the local needs, knowledge and aspirations is key to further engagement with the communities. Professor Buccellati has particularly highlighted this:

"It was vital for us to have a mutual respectful relationship with the locals and trust them because we "archaeologists" can teach them about Urkesh but they can teach us about Mozan"

This aligns with McDavid [19] who also highlights the need for self-reflection by the social analysts and that any social actor should be seen as a part of the social process analysis. Creating local focal points is essential to establish trust and build further community-based activities. It is useful to bring an evidence-based approach to scientific committees regarding decisions about the development of the archaeological work when used as a cultural heritage project as this can lead to better engagement with policy makers and help with further funding. In projects that aim to achieve soft power outcomes, such as social change, mutual trust and understanding, etc., every group needs to feel included and be heard as part of the decision-making process, infrastructure and development. This should be planned from beginning to ensure inclusive growth and sustainability, tying in to the UN Sustainability Goal 
16 , if possible. In this project, this has been addressed in the design of the cultural based community development programme, taking into consideration the conservative dynamics of the relationships in the Gate of Urkesk to ensure the participation of everyone (women/men, youth/oldies/children, Arabs/Kurds, community members and members of local authorities, like the municipality or the mayor). The emphasis should be on stressing the multivocality concept of Hodder [10] and the concepts of cultural diplomacy, as these allow individuals' and communities' voices to be heard, to share with others and create mutual understanding and tolerance.

The work and approach of this case study to include women and have their voice heard needed careful handling to ensure the intangible heritage was developed and promoted as well as the tangible heritage. This is important if there is to be economic and social sustainability for marginalised groups. Risk and assumptions could have been calculated better, especially when the majority of the work done under the umbrella of the Gate of Urkesh was during what the so-called "Arab Spring".

\section{Conclusions}

This article demonstrates that mobilising a community archaeology project can be a useful soft power tool to support an inclusive process within isolated and diverse communities, leading to growth in tangible and intangible cultural heritage. We discussed how community archaeology can deal with the nature, cause and consequences of social exclusion and conflict, empower social and cultural participation and discuss its soft power in enhancing opportunities, access to resources while empowering everyone's voice and respect of rights. Communities engaged with decisions and activities related to community archaeology initiate a dialogue amongst them at first and then with others in order to validate their stories which leads to greater awareness of people's common visions, values, attitudes, fears and hopes feeding in greater understanding in creating a shift in communities' thinking and attitudes towards participation, partnership and inclusion. Community archaeology as a figurative vehicle can empower individuals and communities as it supports creating cultural participation in people to come together, discuss their past, present and future in order to build the integrated bridges between who they are and who they want to become; reducing the risk of further conflict.

The model of community archaeology used in Mozan and the Gate of Urkesh is still a matter of choice and left completely to the willingness of the archaeological missions working there, albeit, in this case with a strong vision for inclusion from the leader. Mozan is a rare example and not constrained by any kind of regulations. The case of Mozan reflects the need for new local/Syrian legislations and regulations to ensure sustainability and achieve a balance between conservation of the site and local development of people, groups and inclusive growth in the terms of possible cultural tourism. This case serves as one example-it does not necessarily mean it could be replicated in every other conflict zone around the world-but it does offer a case study example of an approach to conflict resolution, sustainable development through cultural heritage development and social inclusion. The need for more sustainable networks led by locals is key to success and social change and follows the models deployed by foreign and commonwealth offices in cultural diplomacy terms. As said by a member of the archaeological mission: "Depending on the local organic development is not enough, if we aim to sustain an integral development there must be solid governmental policies and regulations that support and enable communities"; these too could be linked better to civil society organisations and tied into the UN Sustainable Development Goal 16 to help attract outside funding that could help the entrepreneurial growth skills of some of the women's groups and other groups that have formed to ensure access to justice, peace and strengthening institutions in support.

In developing skills such as trust, confidence, resilience and empowerment people can be enabled through culture to develop networks, and develop together rather than be isolated by geographies of exclusion leading to sustainable development for inclusive cultural heritage, though, as we can see, this is still in its infancy. 
Author Contributions: Conceptualization, Y.M. and G.M.; Data curation, Y.M.; Formal analysis, Y.M. and G.M.; Investigation, Y.M. and G.M.; Methodology, Y.M. and G.M.; Project administration, Y.M.; Supervision, G.M.

Funding: This research drew some of our expertise from working with the British Council on the project Arts, Culture and Soft Power: Developing an Evidence Base; British Council: London, UK, 2017, $£ 9000$ and The Contribution of Art and Culture to Global Security and Stability; British Council: London, UK, 2018, $\mathbf{1 1 0 , 0 0 0}$. One of the case studies was based on creative projects in Syria.

Conflicts of Interest: The authors declare no conflict of interest.

\section{References}

1. Armitage, R.; Nye, J. CSIS Commission on Smart Power: A Smarter, More Secure America; The CSIS Press: Washington, DC, USA, 2007.

2. Nye, J. Public diplomacy and soft power. Ann. Am. Acad. Political Soc. Sci. 2008, 616, 94-109. [CrossRef]

3. Marshall, Y. What is community archaeology? World Archaeol. 2002, 34, 211-219. [CrossRef]

4. Shackel, A.P. Working with communities: Heritage development and applied archaeology. In Places in Mind: Public Archaeology as Applied Anthropology; Taylor \& Francis Books, Inc.: Leiden, The Netherlands, 2004.

5. McPherson, G.; McGillivary, D.; Mamattah, S.; Cox, T.; Normann, K. Arts, Culture and Soft Power: Developing an Evidence Base; British Council: London, UK, 2017.

6. Grima, R. But Isn't All Archaeology 'Public' Archaeology? Public Archaeol. 2016, 15, 50-58. [CrossRef]

7. Merriman, N. Public Archaeology; Routledge: New York, NY, USA, 2004.

8. Brooks, M. Public Archaeology with a Doukhobor Descendent Community. Master's Thesis, University of Sasksatechewan, Saskatoon, SK, Canada, November 2005.

9. Green, L.; Green, D.; David, R.; Góes, N. Indigenous knowledge and archaeological science: The challenges of public archaeology in the Reserve Uaçá. J. Soc. Archaeol. 2003, 3, 366-398. [CrossRef]

10. Hodder, J. Multivocality and social archaeology. In Evaluating Multiple Narratives: Beyond Nationalist, Colonialist, Imperialist Archaeologies; Habu, J., Fawcett, C., Matsunaga, J.M., Eds.; Springer Science and Business Media, LLC: Berlin, Germany, 2008.

11. Lewis, R. Cultural Heritage for Inclusive Growth; British Council: London, UK, 2018.

12. DFID. Building Stability Overseas Strategy. 2011. Available online: https://www.gov.uk/government/ uploads/system/uploads/attachment_data/file/67475/Building-stability-overseas-strategy.pdf (accessed on 3 February 2019).

13. Richardson, L.-J.; Sánchez, J.A. Do you even know what public archaeology is? Trends, theory, practice, ethics. World Archaeol. 2015, 47, 194-211. [CrossRef]

14. Albrecht, P.; Jackson, P. State-building through security sector reform: The UK intervention in Sierra Leone. Peacebuilding 2014, 2, 83-99. [CrossRef]

15. Winter, T. Heritage diplomacy. Int. J. Herit. Stud. 2015, 21, 997-1015. [CrossRef]

16. LeBaron, M. Culture and Conflict. Available online: https://www.beyondintractability.org/essay/culture conflict (accessed on 21 August 2019).

17. Cavan Local Authorities. A Guide for Local Authority Staff Elected Members; Social Inclusion Hand Book; Cavan Local Authorities: Cavan, Ireland, 2009.

18. Mac David, C. Descendants, decision, and power: The public interpretation of the archaeology of Levi Jordan plantation. Hist. Archaeol. 1997, 31, 114-131. [CrossRef]

19. McDavid, C. From "Public Archaeologist" to "Public Intellectual": Seeking Engagement Opportunities Outside Traditional Archaeological Arenas. Hist. Archaeol. 2011, 45, 24-32. [CrossRef]

20. Waterton, E.; Smith, L. The recognition and misrecognition of community heritage. Int. J. Herit. Stud. 2010, 16, 4-15. [CrossRef]

21. Trigger, G.B. Alternative Archaeologies: In Historical Perspective. In Evaluating Multiple Narratives: Beyond Nationalist, Colonialist, Imperialist Archaeologies; Habu, J., Fawcett, C., Matsunaga, M.J., Eds.; Springer Science and Business Media, LLC: Berlin, Germany, 2008.

22. Clarke, A. The ideal and the real: Cultural and personal transformation of archaeological research on Groote Eylante, Northern Australia. World Archaeol. 2002, 34, 249-264. [CrossRef]

23. Smith, L. Uses of Heritage; Routledge: London, UK, 2006. 
24. Smith, L.; Campbell, G. Nostalgia for the future': Memory, nostalgia and the politics of class. Int. J. Herit. Stud. 2017, 23, 612-627. [CrossRef]

25. McPherson, G.; Mamattah, S.; Moore, A.; Cifuentes, G.; Moualla, Y. The Contribution of Art and Culture to Global Security and Stability; British Council: London, UK, 2018.

26. Lederach, J.P. The Moral Imagination USA; Oxford University Press: Oxford, UK, 2005.

27. Smith, L. 'We are ... we are everything': The politics of recognition and misrecognition at immigration museums. Mus. Soc. 2017, 15, 69-86. [CrossRef]

28. McKercher, B. Towards a Classification of Cultural Tourists. Int. J. Tour. Res. 2002, 4, 29-38. [CrossRef]

29. Babbie, E. The Basics of Social Research; Wadsworth Publishing: Belmont, CA, USA, 2017.

30. McGill, A.E. Learning from cultural engagements in community-based heritage scholarship. Int. J. Herit. Stud. 2018, 24, 1068-1083. [CrossRef]

31. Mathieson, J.; Popay, J.; Enoch, E.; Escorel, S.; Hernandez, M.; Johnston, H.; Rispel, L. Social Exclusion Meaning, Measurement and Experience and Links to Health Inequalities. 2008. Available online: https://www.who. int/social_determinants/media/sekn_meaning_measurement_experience_2008.pdf.pdf?ua=1 (accessed on 21 August 2019).

32. Fitzpatrick, C.; Engels, D. Leaving no one behind: A neglected tropical disease indicator and tracers for the Sustainable Development Goals. Int. Health 2016, 8, i15-i18. [CrossRef] [PubMed]

33. Sandell, R. Museums as Agents of Social Inclusion. Mus. Manag. Curatorship 1998, 17, 401-418. [CrossRef]

34. Díaz-Andreu, M.; Ruiz, A. Interacting with Heritage: Social Inclusion and Archaeology in Barcelona. J. Community Archaeol. Herit. 2017, 4, 53-68. [CrossRef]

35. Korza, P.; Schaffer, B. Artists Engaging in Social Change. 2010. Available online: https://www.giarts.org/sites/ default/files/Trend-or-Tipping-Point-Arts-Social-Change-Grantmaking.pdf (accessed on 21 August 2019).

36. Flinn, J.; McPherson, G. Culture Matters: The Role of Art and Culture in the Development of Social Capital. Available online: https://www.researchgate.net/publication/254606836_Culture_Matters_the_Role_of_Art_ and_Culture_in_the_Development_of_Social_Capital $\backslash T 1 \backslash$ textquoteright (accessed on 21 August 2019).

(C) 2019 by the authors. Licensee MDPI, Basel, Switzerland. This article is an open access article distributed under the terms and conditions of the Creative Commons Attribution (CC BY) license (http://creativecommons.org/licenses/by/4.0/). 